F. Reprod. Fertil. (1963) 5, 447-449

BRIEF COMMUNICATION

\title{
UNILATERAL HORMONE EFFECT IN THE MARSUPIAL TRICHOSURUS VULPECULA
}

\author{
SANDRA M. VON DER BORGH* \\ Department of Zoology, University of Adelaide, Australia
}

(Received 1st March 1963)

Trichosurus vulpecula Kerr (the Brush Possum) is a monovular and polyoestrous marsupial in which the two uteri are completely separate. Pilton \& Sharman (1962) reported that in non-pregnant females, the uterus under the corpus luteum often exceeded the other in size. This observation formed the basis of the present investigation.

TABLE 1

WEIGHTS OF UTERI IN FEMALE Trichosurus vulpecula 8 TO 10 DAYS POSTOESTRUS

\begin{tabular}{|c|c|c|c|}
\hline \multirow{2}{*}{ Description } & \multicolumn{3}{|c|}{ Weight of uterus $(\mathrm{g})$} \\
\hline & Left & Right & $\mathrm{d}_{1}=(L-R)$ \\
\hline \multirow[t]{2}{*}{$\begin{array}{l}\text { Corpus luteum on left } \\
\text { ovary }\end{array}$} & $\begin{array}{l}1 \cdot 061 \\
1 \cdot 244 \\
0.971 \\
1.112 \\
1 \cdot 866 \\
0.911 \\
1 \cdot 652 \\
1.897\end{array}$ & $\begin{array}{l}0 \cdot 845 \\
0 \cdot 919 \\
0.708 \\
0.885 \\
1 \cdot 780 \\
0.735 \\
1 \cdot 450 \\
1 \cdot 662\end{array}$ & $\begin{array}{c}0.216 \\
0.325 \\
0.263 \\
0.227 \\
0.086 \\
0.176 \\
0.202 \\
0.235 \\
\overline{\mathbf{d}}_{1}=0.21625\end{array}$ \\
\hline & Left & Right & $\mathbf{d}_{2}=(L-R)$ \\
\hline $\begin{array}{l}\text { Corpus luteum on right } \\
\text { ovary }\end{array}$ & $\begin{array}{l}1 \cdot 337 \\
1 \cdot 408 \\
1.500 \\
1.578\end{array}$ & $\begin{array}{l}1 \cdot 272 \\
1 \cdot 404 \\
1 \cdot 372 \\
1 \cdot 693\end{array}$ & $\begin{array}{c}0.065 \\
0.004 \\
0 \cdot 128 \\
-0 \cdot 115 \\
\overline{\mathrm{d}}_{2}=0.02050\end{array}$ \\
\hline
\end{tabular}

In twelve females killed at 8 to 10 days post-oestrus, it was found that where the corpus luteum was on the left ovary, the left uterus averaged $19 \%$ heavier than the right, but where the corpus luteum was on the right ovary the left uterus averaged only $1 \%$ heavier than the right (see Table 1 ). Thus it seemed that basically the left uterus was heavier than the right (the 'left side effect') and that superimposed on this was a 'corpus luteum effect', whereby there was an enlargement in the uterus under the corpus luteum.

* Present address: Physiological Laboratory, Downing Street, Cambridge. 
In spite of the small number of animals it was shown that the left uterus was significantly heavier than the right, allowing for the 'corpus luteum effect' $\left(\mathrm{t}_{10}=4.70, P<0.001\right)$, and that, conversely, when allowance was made for the 'left side effect', the corpus luteum caused a significant increase in weight of the associated uterus $\left(\mathrm{t}_{10}=3.94, P<0.01\right)$.

These results suggested that a hormone from the ovulating ovary reached the associated uterus either by way of the Fallopian tube or by direct diffusion. To test the former possibility the Fallopian tube under the mature follicle was
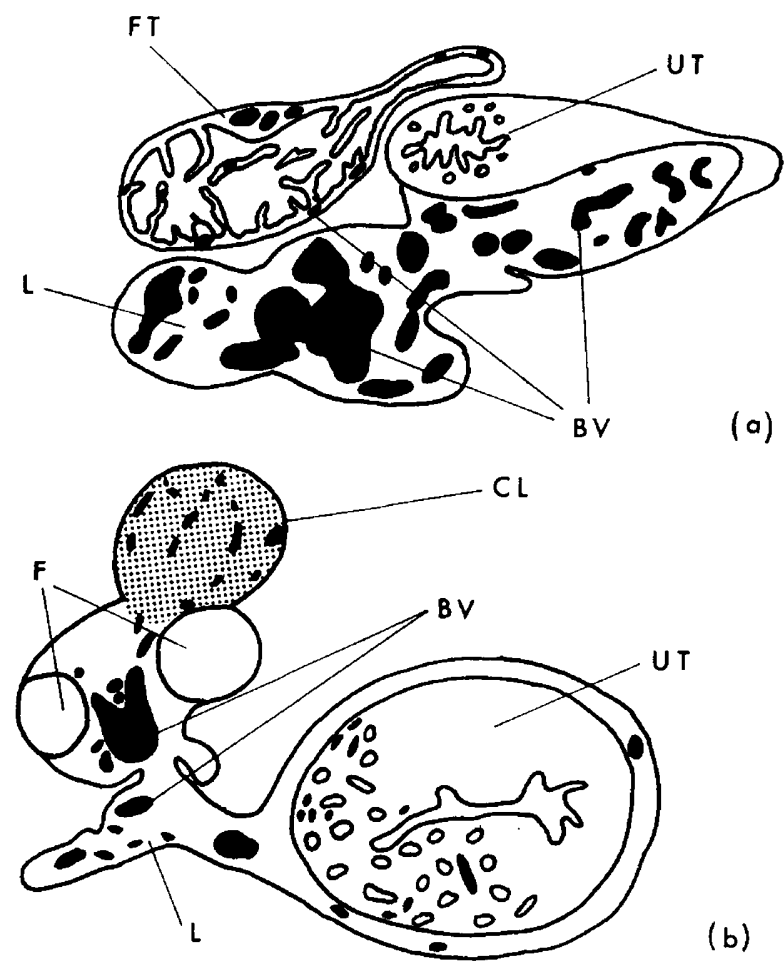

(a)

(b)

TeXT-FIG. 1. Transverse section through top of uterus above the level of the ovary, showing the Fallopian tube and the ligament which connects ovary and uterus (a). Transverse section through uterus and ovary showing connecting vascular ligament $(b) . B V=B l o o d$ vessels; $\mathrm{CL}=$ Corpus luteum; $\mathbf{F}=$ Follicle; $\mathbf{F T}=$ Fallopian tube $\mathrm{L}=$ Ligament; $\mathrm{UT}=$ Uterus.

closed in six animals which were then killed at 8 to 10 days post-oestrus. This procedure did not significantly alter the 'corpus luteum effect', and since the ovary lies close to the uterus and is connected to it by thick vascular tissue (Plate 1 and Text-fig. 1), it seems most likely that the hormone reaches the uterus by direct diffusion from the ovary.

The mitotic rate in the uterus was counted in fixed and stained sections. On the same side as the new corpus luteum at 2 days post-oestrus the rate was significantly higher in two females $(P<0.02)$ but not in another female $(0.05<$ $P<0 \cdot 1)$. Increase in mitotic rate is a sensitive and specific assay for oestrogens (Martin \& Claringbold, 1960), so it is likely that the 'corpus luteum effect' is due to cell proliferation following the local action of oestrogen. Increase in 


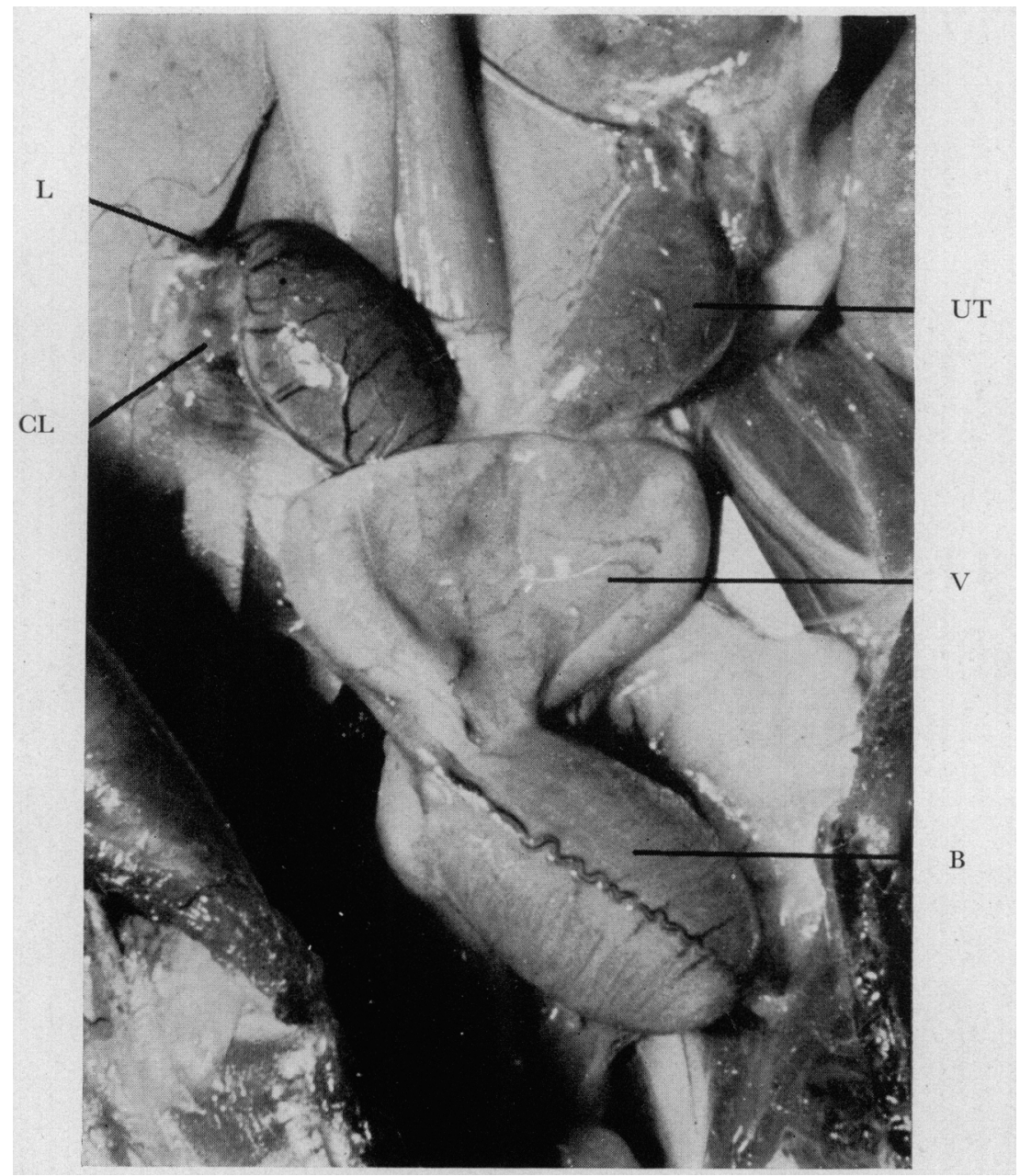

Reproductive system of Trichosurus iulpecula showing proximity of ovary to uterus. $\mathrm{B}=$ Bladder $; \mathrm{CL}=$ Corpus luteum; $\mathbf{L}=$ Ligament $; \mathrm{UT}=$... Uterus $; \mathrm{V}=$ Vaginal complex.

(Facing p. 448) 
fluid content of one uterus is unlikely to be responsible, since in two females both uteri lost the same percentage of weight on dehydration.

A more thorough investigation of this phenomenon is planned for a later date.

I wish to thank Dr G. B. Sharman for advice and supervision, Mr N. Stenhouse, C.S.I.R.O., Division of Mathematical Statistics, Adelaide, Australia, for statistical analysis of the data, Mr J. Merchant for technical assistance and Professor I. Chester-Jones for advice on the manuscript. The work was carried out while I held a C.S.I.R.O. Junior Postgraduate Studentship and some finance was provided by a grant from the Nuffield Foundation.

\section{REFERENCES}

Martin, L. \& Glaringbold, P. J. (1960) The mitogenic action of oestrogens in the vaginal epithelium of the ovariectomized mouse. 7. Endocrin. $20,173$.

Pilton, P. E. \& Sharman, G. B. (1962) Reproduction in the marsupial Trichosurus vulpecula. J. Endocrin. $25,119$. 